\title{
Synthesis and Characteristics of Chelating Fibers Containing Imidazoline Group or Thioamide Group
}

\author{
RUIXIA LIU, ${ }^{1}$ YI LI, ${ }^{2}$ HONGXIAO TANG ${ }^{1}$ \\ ${ }^{1}$ State Key Laboratory of Environmental Aquatic Chemistry, Research Center for Eco-Environmental Sciences, Chinese \\ Academy of Sciences, P.O. Box 2871, Beijing 100085, China \\ ${ }^{2}$ Central Iron and Steel Research Institute, Ministry of Metallurgical Industry, Beijing 100081, China
}

Received 7 September 2000; accepted 16 April 2001

\begin{abstract}
Two types of chelating fibers containing an imidazoline or thioamide group were prepared through the functionalization of hydrazine-modified polyacrylonitrile fiber by ethylenediamine and through the amination and sulfurization reaction of the hydrazine-modified polyacrylonitrile fiber under appropriate conditions, respectively. It is shown that the reaction temperature, time, and agent concentration are the dominant factors in the synthesis of fibrous sorbents. The increase of the ethylenediamine concentration from 33 to $45 \%(\mathrm{v} / \mathrm{v})$ at $95-98^{\circ} \mathrm{C}$ results in a twofold higher increase of the fibrous sorbent with the imidazoline group, and a doubling of the reaction time from 2 to $4 \mathrm{~h}$ leads to a weight increase of the fibrous sorbent from 10 to $25 \%$ (w/w). Raising the temperature by about $5^{\circ} \mathrm{C}$ significantly accelerates the amination reaction of the hydrazine-modified fiber, but the temperature is an insensitive factor in the thioamidefunctionalized reaction of the aminated fiber. The introduction of a thioamide or imidazoline group is further verified by IR spectroscopy analysis. X-ray diffraction spectroscopy indicates the absolute disappearance of crystalline peaks for the fibers containing an imidazoline or thioamide group. However, the crosslinking reaction of the polyacrylonitrile fiber by hydrazine may make up for the effect of the crystallinity on the mechanical strength of the fibers, and the surface crackles of fibrous sorbents are not found by SEM photographs. The adsorption experiment results show that the newly prepared sorbents have high sorption capacities for noble metals in a high acidity, and it is also proved that $\mathrm{Au}$ (III) loaded on the chelating fibers may be reduced to $\mathrm{Au}(0)$. $\odot 2002$ John Wiley \& Sons, Inc. J Appl Polym Sci 83: 1608-1616, 2002
\end{abstract}

Key words: chelating fibers; imidazoline groups; thioamide group; synthesis; characteristics; adsorption properties; noble metal

\section{INTRODUCTION}

Platinum group and gold elements have been widely applied to the chemical, electronics, and

\footnotetext{
Correspondence to: Dr. R. Liu (rachel@mail.rcees.ac.cn).

Contract grant sponsor: Natural Sciences Foundation of China; contract grant number: 29977027.

Journal of Applied Polymer Science, Vol. 83, 1608-1616 (2002)

(c) 2002 John Wiley \& Sons, Inc.

DOI 10.1002/app.10156
}

aerospace industries due to their corrosion resistance, oxidation resistance, and excellent catalytic properties. Thus, the developments in the separation and preconcentration techniques of trace noble metals from various samples for raw material recovery has attracted considerable attention. ${ }^{1-3}$ In recent years the solid-phase adsorption technique has become increasing popular ${ }^{4,5}$ compared to the traditional methods such as fire assay, coprecipatation, and solvent extraction. 
Ion exchange (or chelating) resins are being developed continuously. Polyacrolein-isonicotinic acid hydrazone and poly(acrylic acid)-thiohydrazide resins $^{6}$ and imdazoline-based ${ }^{7,8}$ and formazan- and tetrazolium-containing ${ }^{9-11}$ ion exchangers show promising adsorption capacity for noble metals. However, the use of these gel-structure granular exchangers and porous copolymers in the separation and preconcentration of trace noble metals is limited because of their slow sorption rate. Fibrous sorbents with various functional groups, which have good kinetic properties and high adsorption efficiency, are being developed and applied in the recovery of useful elements, ${ }^{12}$ water and air purification, ${ }^{13,14}$ and separation and preconcentration of trace elements. ${ }^{15-17}$

The application of the solid-phase extraction technique with a fibrous sorbent is largely dependent on the development of new adsorptive material. According to Pearson's hard and soft acidbase concept, the promising selective sorbents toward noble metal ions are expected from the polymers containing functional groups with donor $\mathrm{N}$ and $\mathrm{S}$ atoms. Thus, the objective of the present study is to develop two types of chelating fibers containing an imidazoline group or thioamide group for the adsorption of noble metal ions. The synthetic route for the chelating fibers with a thioamide or imidazoline group and the dominant factors in the synthetic reaction are elucidated in detail. The chemical functional groups, element composition, and crystalline and surface characteristics of these fibrous sorbents are investigated. The adsorption properties for noble metals are compared.

\section{EXPERIMENTAL}

\section{Instruments and Reagents}

The various fibers were ground with spectral grade $\mathrm{KBr}$ in an agate mortar, and an aliquot of $400 \mathrm{mg}$ of the powder was taken with a $0.1 \%$ $(\mathrm{w} / \mathrm{w})$ sorbent content. Translucent disks were prepared by pressing the ground material with the aid of an 8-ton pressure bench press. The IR spectra of these materials were obtained on a Perkin-Elmer FTIR-2000 system. The fibrous sorbents were cut into 1-mm units and then simply spread onto a sample holder. The X-ray diffraction spectra of the chelating fibers were recorded with an APD-10 X-ray diffractometer. A
ST-02 elements analyzer and S-520 scanning electron microscope (SEM) were used to determine the element content and investigate the surface characteristics, respectively. A Spectroflame inductively coupled plasma (ICP) argon-plasma emission spectrometer (ICP-AES) was used for the determination of the concentrations of all metal ions. An HZQ-C air-bath shaker was employed to shake the solution. The synthetic reaction was carried out in a three-necked flask.

Standard solutions of noble metals ( $1000 \mathrm{mg} / \mathrm{L})$ were provided by the Research Institute of Noble Metals, Academia Sinica. All other chemicals were analytical grade or better. Deionized water was used throughout the experimental procedure. The polyacrylonitrile fiber (PANF, a common commercial product) was purchased from Chinese Chemical Factory (Beijing).

\section{Synthesis of Chelating Fiber with Thioamide Group}

\section{Step 1: Crosslinking Reaction of PANF by Hydrazine Hydrate}

The PANF (25 g) and $1000 \mathrm{~mL}$ of the waterhydrazine hydrate mixture $(26.5 \% \mathrm{v} / \mathrm{v})$ was reacted in a 1.25 -L flat-flange reaction vessel for $2-2.5 \mathrm{~h}$ at $90-94^{\circ} \mathrm{C}$, suction filtered, washed with ethanol, and dried at $55-60^{\circ} \mathrm{C}$ overnight. ${ }^{18}$ The weight increase of the fiber was $5-8 \%$.

\section{Step 2: Amination of Hydrazine-Modified PANF}

The hydrazine-modified PANF ( $25 \mathrm{~g}$ ) was added to $1000 \mathrm{~mL}$ of $33 \%(\mathrm{v} / \mathrm{v})$ diethylenetriamine solution. The mixture was heated to $95-97^{\circ} \mathrm{C}$ for $8 \mathrm{~h}$. The obtained fiber was cooled and soaked in 0.1 $\mathrm{mol} / \mathrm{L}$ of diluted hydrochloric acid for 1-2 $\mathrm{h}$. Then the product was washed with deionized water until the washing was neutral and dried at 50$60^{\circ} \mathrm{C} .{ }^{19}$ The weight increase of the fiber was $28-$ $34 \%$.

\section{Step 3: Functionalization of Aminated Fiber}

Prior to the functionalization reaction, the above aminated fiber was immersed in $1 \mathrm{~mol} / \mathrm{L} \mathrm{H}_{3} \mathrm{PO}_{4}$ solution for $2-3 \mathrm{~h}$, and a buffer solution ( $\mathrm{pH} 6.8-$ 6.9) was prepared by dissolving $4 \mathrm{~g}$ of $\mathrm{NaH}_{2} \mathrm{PO}_{4}$ - $2 \mathrm{H}_{2} \mathrm{O}$ and $9 \mathrm{~g}$ of $\mathrm{Na}_{2} \mathrm{HPO}_{4} \cdot 12 \mathrm{H}_{2} \mathrm{O}$ in $1000 \mathrm{~mL}$ of deionized water. The functionalized reaction solution was prepared by dissolving $110 \mathrm{~g}$ of $\mathrm{Na}_{2} \mathrm{~S}$ - $9 \mathrm{H}_{2} \mathrm{O}$ in $600 \mathrm{~mL}$ of the above buffer solution. The reaction solution was mixed with $20 \mathrm{~g}$ of the soaked fiber in a 1.25-L flat-flange reaction vessel 


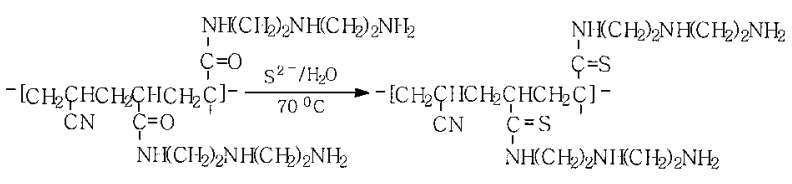

(Aminated fiber)

(Fiber containing thioamide group)

Scheme 1 The synthetic reaction of thioamide-containing chelating fibers based on aminated fiber.

and warmed to $70-72^{\circ} \mathrm{C}$ for $6 \mathrm{~h}$. The final fibrous product was suction filtered, washed with deionized water until no sulfur ions were detected in the washing, and dried at $50-60^{\circ} \mathrm{C}$. The weight increase of the chelating fiber was $13-16 \%$. During the functionalized reaction procedure the $\mathrm{pH}$ value of the reaction system was adjusted and kept in the range of 7.5-8.0 with a mixture of a $\mathrm{H}_{3} \mathrm{PO}_{4}$-buffer solution (1:1 v/v). The functional reaction is briefly expressed in Scheme 1 .

\section{Synthesis of Chelating Fibers with Imidazoline Group}

\section{Step 1: Crosslinking Reaction of PANF by Hydrazine Hydrate}

As the above section described, $25 \mathrm{~g}$ of PANF and $1000 \mathrm{~mL}$ of hydrazine hydrate were reacted in a 1.25-L flat-flange reaction vessel for $2-2.5 \mathrm{~h}$ at $90-94^{\circ} \mathrm{C}$. Then they were suction filtered, washed with ethanol, and dried at $55-60^{\circ} \mathrm{C}$ overnight. ${ }^{18}$

\section{Step 2: Functionalized Reaction of Hydrazine- Modified PANF}

The functionalized reaction solution was prepared by mixing $1 \mathrm{~g}$ of sulfur powder and $800 \mathrm{~mL}$ of $33 \%(\mathrm{v} / \mathrm{v})$ ethylenediamine in a flat-flange reaction vessel and heating to $90^{\circ} \mathrm{C}$. Afterward $20 \mathrm{~g}$ of the dry hydrazine-modified fiber was added to the reaction solution; then the reaction system was warmed to $95-98^{\circ} \mathrm{C}$ for $7 \mathrm{~h}$, cooled, and suction filtered. The fiber was washed with hot deionized water $\left(50-60^{\circ} \mathrm{C}\right)$ and dried at $50-60^{\circ} \mathrm{C}$ overnight. The final chelating fiber was obtained, and the weight increase of the fiber was $55-60 \%$. This synthetic step is shown in Scheme 2.

\section{Determination of Specific Capacity and Distribution Coefficients}

A batch technique was applied to determine the metal binding capacity of the chelating fibers. Typically, $0.10 \mathrm{~g}$ of triplicate chelating fiber sam- ples were equilibrated in $10 \mathrm{~mL}$ of $0.01 \mathrm{~mol} / \mathrm{L}$ $\mathrm{Pt}(\mathrm{IV}), \mathrm{Rh}(\mathrm{III})$, and $\mathrm{Ru}(\mathrm{IV}) ; 10 \mathrm{~mL}$ of $0.02 \mathrm{~mol} / \mathrm{L}$ $\mathrm{Pd}(\mathrm{II}), \operatorname{Ir}(\mathrm{IV})$, and $\mathrm{Os}(\mathrm{IV})$; and $20 \mathrm{~mL}$ of 0.025 $\mathrm{mol} / \mathrm{L} \mathrm{Au}(\mathrm{III})$ salts solution, which were prepared by evaporating appropriate volumes of standard metal solutions (1000 mg/L) to dryness and dissolving the residues in diluted hydrochloric acid (usually $0.1 \mathrm{~mol} / \mathrm{L} \mathrm{HCl}$ ). After the suspension was shaken for $24 \mathrm{~h}$ at $25^{\circ} \mathrm{C}$, the residual concentration of the metal ions in the supernatant was analyzed by the ICP-AES. The binding capacity for the individual metal ion $(Q, \mathrm{mmol} / \mathrm{g}$ or $\mathrm{mg} / \mathrm{g}$ of dry fiber) was calculated in the usual way. The distribution coefficient $(D)$ was also determined by a similar method with $10 \mathrm{~mL}$ of $0.001 \mathrm{~mol} / \mathrm{L}$ metal salt solution in diluted hydrochloric acid.

\section{RESULTS AND DISCUSSION}

\section{Influence of Reaction Conditions on Synthesis}

Figure 1 shows the dominant factors in the synthesis of imidazoline-containing chelating fibers, including the concentration of the ethylenediamine and the reaction time. It is obvious that the ratio of the reaction, measured in units of relative weight increase, is consistent with the ethylenediamine concentration and the reaction time. The increase of the reagent concentration from 33 to $45 \%(\mathrm{v} / \mathrm{v})$ at $95-98^{\circ} \mathrm{C}$ results in a twofold higher increase of the chelating fiber mass and the doubling of the reaction time from 2 to $4 \mathrm{~h}$ leads to a $10-25 \%$ (w/w) weight increase of the fibrous sorbent.

Moreover, the yield of the amination reaction strongly depends on the reaction temperature. As shown in Figure 2(a), raising the temperature by about $5^{\circ} \mathrm{C}$ significantly accelerates the amination reaction of the hydrazine-modified fiber. The mechanical strength of the fiber however decreases with the reaction temperature increase. In general, each of the polymers has its paracrystalline region in which the polymers possess good crystallinity properties. When the reaction tempera-

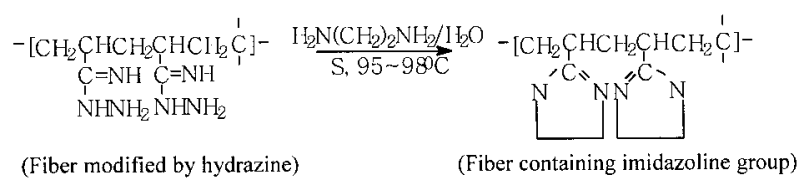

Scheme 2 The synthetic reaction of a fibrous sorbent containing imidazoline based on hydrazine-modified fiber. 

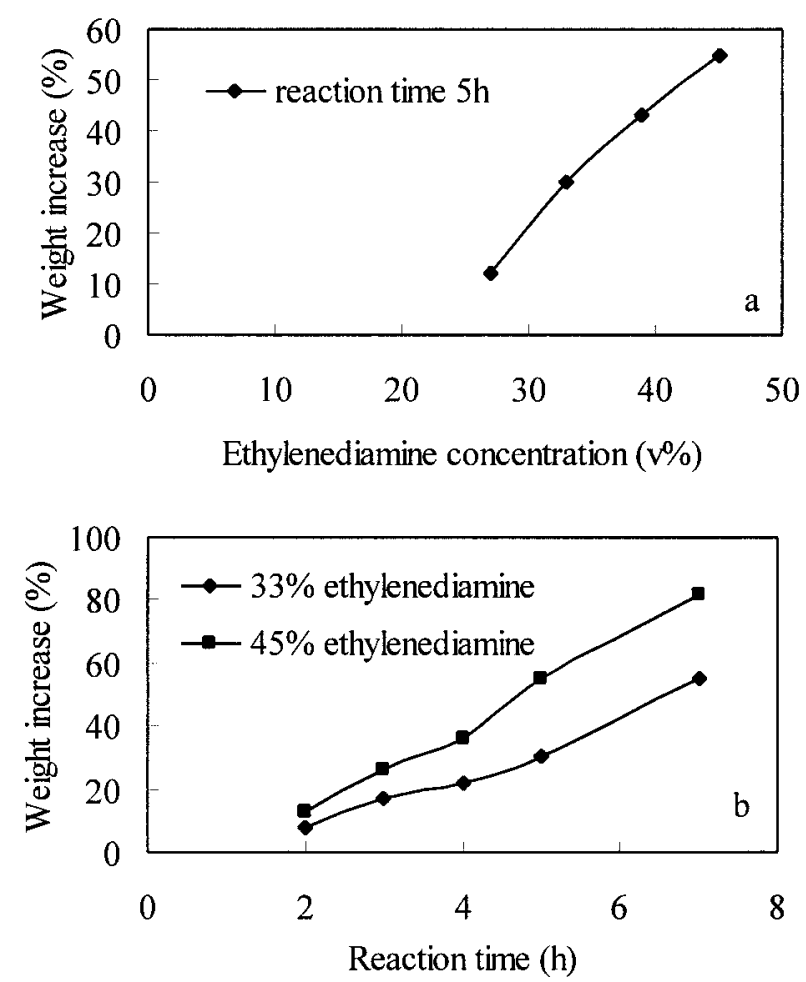

Figure 1 The effect of the (a) ethylenediamine concentration and (b) reaction time on the synthesis of imidazoline-containing chelating fiber at $95-98^{\circ} \mathrm{C}$.

ture is higher and exceeds that of the paracrystalline region, the crystallinity of the fiber is greatly decreased and the mechanical property begins to be inferior. Thus, the best results for the amination reaction are obtained with a temperature range of $95-97^{\circ} \mathrm{C}$. However, the temperature is an insensitive factor in the thioamide-functionalized reaction of aminated fiber. As revealed in Figure 2(b), even if the temperature increases by about $20^{\circ} \mathrm{C}$, the weight increase of the fiber has insignificant changes and the maximum value is $17 \%$ at $70^{\circ} \mathrm{C}$.

\section{IR Spectrum Analysis for Chelating Fiber}

The IR spectra of various products during the synthesis of thioamide- and imidazoline-containing chelating fibers are shown in Figure 3. According to the reference information, ${ }^{20,21}$ the absorption peaks can be assigned as in Table I. For PANF the absorption peaks of $\mathrm{C} \equiv \mathrm{N}$ and $\mathrm{C}=\mathrm{O}$ in the ester stretching vibration at 2242 and 1733 $\mathrm{cm}^{-1}$ as well as the broad absorption bands of $\mathrm{O}-\mathrm{H}$ and $\mathrm{C}-\mathrm{O}-\mathrm{CH}_{3}$ groups at $3300-3600$ and 1250-1171 $\mathrm{cm}^{-1}$ indicate the raw PANF as a tripolymer containing carboxyl, methyl ester, and nitrile groups. After the raw PANF is crosslinked by hydrazine, the absorption band at 3300-3600 $\mathrm{cm}^{-1}$ shifts to a shorter wavenumber and the intensity of the peak greatly increases. A sharp peak contributing to $\mathrm{N}-\mathrm{H}$ group stretching vibration appears at $3347 \mathrm{~cm}^{-1}$. A new peak at $1561 \mathrm{~cm}^{-1}$ corresponds to $-\mathrm{NH}$ bending motion combined with a - CN stretching vibration of the $\mathrm{C}(=\mathrm{NH})-\mathrm{NH}$ - group. In addition, the intensity of $\mathrm{C} \equiv \mathrm{N}$ and $\mathrm{C}=\mathrm{O}$ in ester stretching vibration peaks is reduced. This shows that the crosslink reaction occurs in $\mathrm{C} \equiv \mathrm{N}$ and $\mathrm{C}=\mathrm{O}$ in the ester and results in the formation of the hydrazide group. In the fiber aminated by diethylenetriamine, it is observed that the stretching vibration peak of $\mathrm{C}=\mathrm{O}$ in the ester at $1731 \mathrm{~cm}^{-1}$ disappears completely and the content of the $\mathrm{C} \equiv \mathrm{N}$ group decreases, which are respectively attributed to the amination of the ester group and hydrolysis of the nitrile group. The introduction of the thioamide group into the fibrous sorbent is verified by $\mathrm{C}=\mathrm{S}$ stretching vibration peaks at 1218 and $883 \mathrm{~cm}^{-1}$. For the imidazoline-containing fiber the widths of the absorption bands at
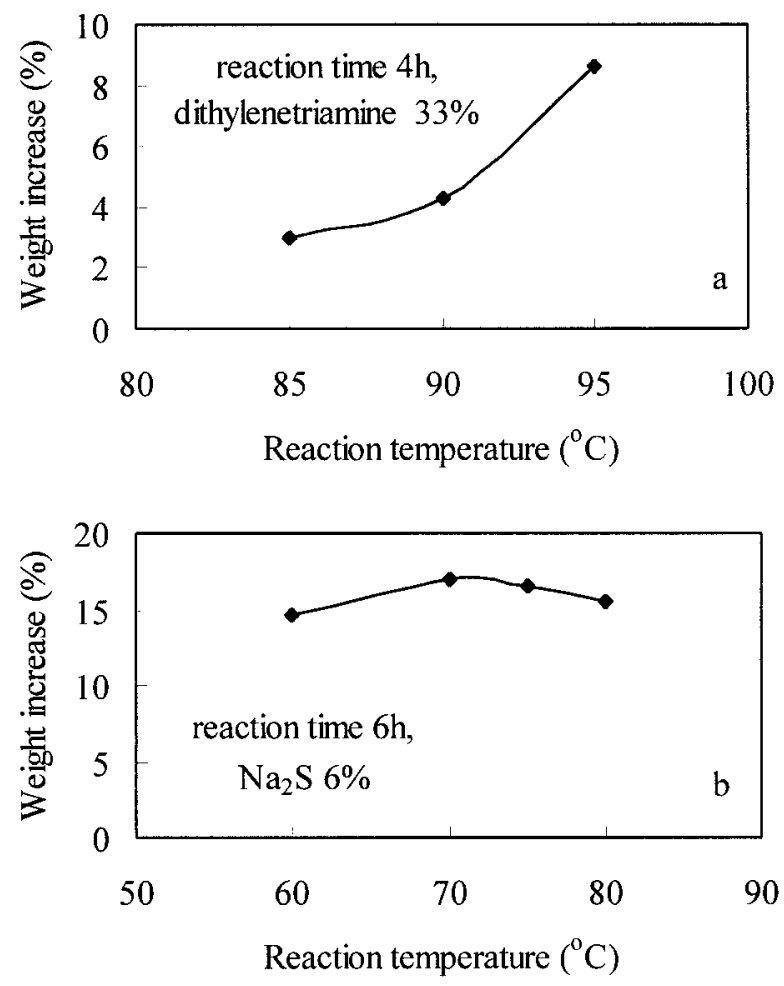

Figure 2 The effect of the temperature on the (a) amination reaction of hydrazine-modified fiber and (b) thioamide-functionalized reaction. 


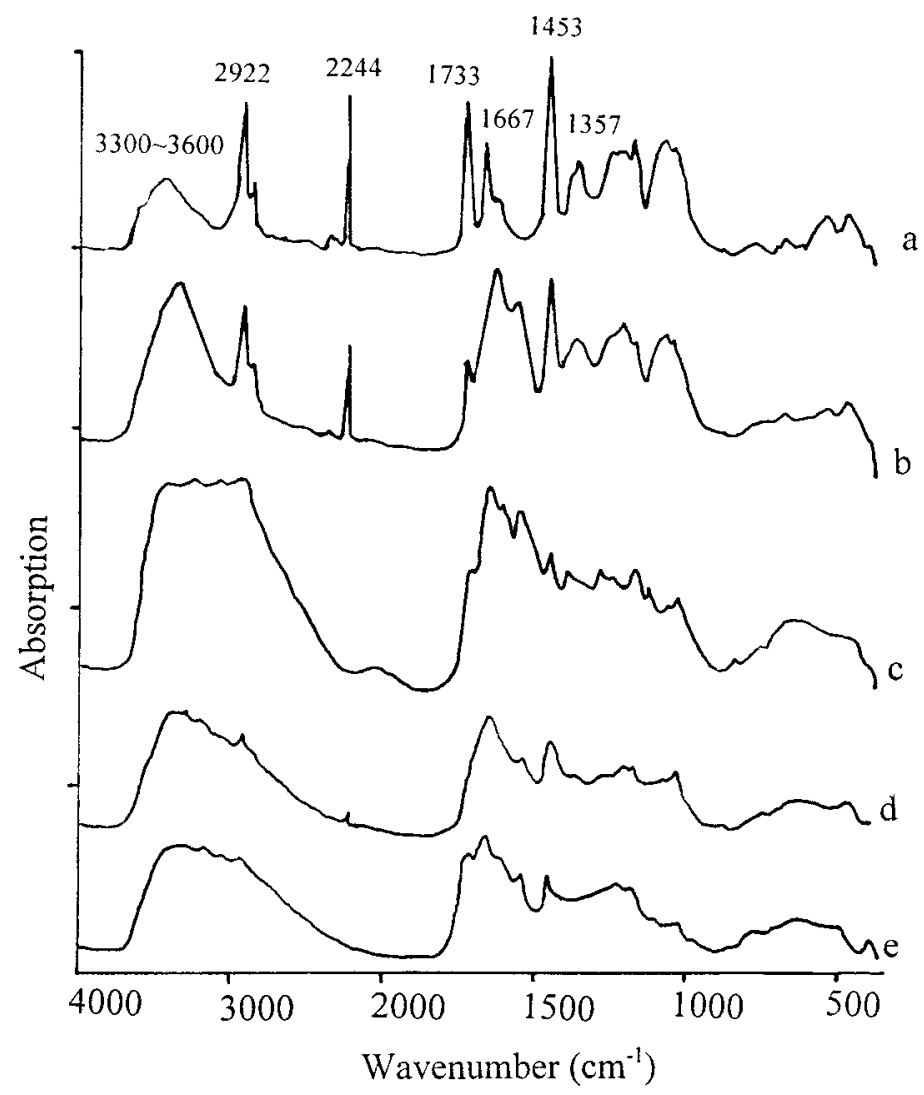

Figure 3 IR spectra of PANF (spectrum a), hydrazine-modified fiber (spectrum b), imidazoline-containing chelating fiber (spectrum c), aminated fiber (spectrum d), and thioamide-containing chelating fiber (spectrum e).

$3700-3100$ and $1734-1544 \mathrm{~cm}^{-1}$ obviously increase compared to those of the hydrazine-modified fiber and the peak intensity of the $\mathrm{C} \equiv \mathrm{N}$ stretching vibration and $\mathrm{CH}_{3}$ bending vibration at 2244 and $1454 \mathrm{~cm}^{-1}$, respectively, greatly decreases. This shows that the imidazoline group is introduced to the fibrous sorbent and the functionalized reaction occurs in nitrile and methyl ester groups.

\section{Character and Element Content of Fibrous Sorbents}

The results of the elemental analysis show the subsequent loss of nitrogen content from 25.9 to $14.47 \%$ and the increase of the oxygen content from 6.83 to $13.7 \%$ during the imidazoline-functionalized reaction of hydrazine-modified fiber. These behaviors mainly correspond to the formation of a cyclic structure and the conversion and hydrolysis of nitrile groups. The amination reaction of hydrazine-modified fiber leads to the remarkable increase of the oxygen content, showing the conversion of nitrile into carboxyl in the presence of an amination agent. The thioamide-functionalized reaction results in the decrease of the oxygen and nitrogen contents; the introduction of sulfur is confirmed (Table II).

The X-ray diffraction spectra indicate that PANF exhibits a good crystalline property; but through the chemical modification of the fibrous sorbent, the crystallinity of various products at several reaction stages becomes inferior. As shown in Figure 4, the intensity of the crystalline peaks successively decreases during the reaction, and the crystalline peaks of the imidazoline- and thioamide-containing chelating fibers completely disappear. Generally, with reaction processing and formation of a cyclic structure the polar interaction between the molecule and the activity of molecular chain decrease; thus, the regular degree or crystallinity of the polymer becomes inferior. However, the crosslinking reaction of PANF by hydrazine may make up for the effect of the crystallinity on the mechanical strength of the 
Table I Classification of IR Spectra for Various Products during Synthetic Process

\begin{tabular}{|c|c|c|c|c|c|}
\hline \multirow[b]{2}{*}{ Assignment* } & \multicolumn{5}{|c|}{ Wavenumber $\left(\mathrm{cm}^{-1}\right)$} \\
\hline & PANF & $\begin{array}{c}\text { Hydrazine- } \\
\text { Modified } \\
\text { Fiber }\end{array}$ & $\begin{array}{c}\text { Aminated } \\
\text { Fiber }\end{array}$ & $\begin{array}{c}\text { Imidazoline- } \\
\text { Containing Fiber }\end{array}$ & $\begin{array}{c}\text { Thioamide- } \\
\text { Containing Fiber }\end{array}$ \\
\hline$\nu(\mathrm{O}-\mathrm{H})$ & $3300-3600$ & $3300-3600$ & $3300-3600$ & $3100-3700$ & $3300-3600$ \\
\hline$\nu(\mathrm{N}-\mathrm{H})$ & - & 3347 & 3356 & 3422 & 3393 \\
\hline$\nu\left(\mathrm{CH}_{2}\right)$ & 2922 & 2927 & 2933 & 2942 & 2930 \\
\hline$\nu(\mathrm{CH})$ & 2853 & 2853 & - & - & - \\
\hline$\nu(\mathrm{C} \equiv \mathrm{N})$ & 2244 & 2244 & 2244 & - & 2243 \\
\hline$\nu(\mathrm{C}=\mathrm{O})$ & 1733 & 1731 & 1645 & 1720 & 1642 \\
\hline$\nu(\mathrm{C}=\mathrm{N})$ & 1667 & 1631 & - & 1651 & - \\
\hline$\nu(\mathrm{N}-\mathrm{H}), \delta(\mathrm{C}-\mathrm{N})$ & - & 1561 & 1567 & 1544 & 1545 \\
\hline$\delta(\mathrm{CH}), \delta\left(\mathrm{CH}_{3}\right)$ & 1453 & 1452 & 1452 & 1454 & 1447 \\
\hline$\delta\left(\mathrm{CH}_{2}\right)$ & 1357 & 1369 & - & - & - \\
\hline$\delta_{S}(\mathrm{CH})$ & - & - & 1393 & 1388 & - \\
\hline$\nu(\mathrm{C}-\mathrm{O})$ & - & - & 1303 & 1292 & - \\
\hline$\nu(\mathrm{C}=\mathrm{S})$ & - & - & - & - & 1218,883 \\
\hline$\nu\left(\mathrm{C}-\mathrm{O}-\mathrm{CH}_{3}\right)$ & $1250-1171$ & - & - & - & - \\
\hline$\nu(\mathrm{C}-\mathrm{N})$ & - & 1208 & 1039 & - & 1033 \\
\hline
\end{tabular}

$\nu$, stretching vibration; $\delta$, bending vibration; $\delta_{S}$, scissor vibration.

chelating fibers. Furthermore, the surface appearance from the SEM photographs of the fibers obtained at various reaction stages has insignificant differences, and the surface crackle of fibrous sorbents was not found.

\section{Adsorption Properties of Chelating Fibers for Noble Metals}

The adsorption ability of chelating fiber for metal ions greatly depends on the type and content of functional groups of the sorbent. The chelating sorbent with a $\mathrm{S}$ - or $\mathrm{N}$-donor atom can strongly bind noble metals. It has been reported that the dynamic adsorption capacities of poly(acrylacylisothiourea) chelating fiber for $\mathrm{Au}(\mathrm{III}), \mathrm{Pd}(\mathrm{IV})$, and $\mathrm{Ru}(\mathrm{IV})$ are 150,100 , and $50 \mathrm{mg} / \mathrm{g}$, ${ }^{5}$ respectively, and the binding capacities of polythioether-type cotton fibers for $\mathrm{Au}(\mathrm{III}), \mathrm{Pd}(\mathrm{II})$, and $\mathrm{Pt}(\mathrm{IV})$ in 1-2 $\mathrm{mol} / \mathrm{L} \mathrm{HCl}$ are $1.1-1.82,0.64-1.50$, and $0.10-0.56$ $\mathrm{mmol} / \mathrm{g}$, respectively. ${ }^{22}$ In this present work the maximum loading capacities of the imidazolineand thioamide-containing chelating fibers and PANF for the individual noble metals are presented in Table III. The results show that the introduction of chemical functional groups leads to the increase of the binding capacity for noble metals. For all tested noble metals the imidazoline-containing chelating fiber exhibits higher adsorption capacities compared to those of the thioamide-containing chelating fiber and the above literature results. The specific capacities for noble metal ions decrease in the following sequence: $\mathrm{Au}(\mathrm{III})>\mathrm{Pd}(\mathrm{II})>\mathrm{Os}(\mathrm{IV}) \sim \mathrm{Ir}(\mathrm{IV})>\mathrm{Pt}(\mathrm{IV})$ $>\mathrm{Rh}(\mathrm{III})>\mathrm{Ru}(\mathrm{IV})$. In the thioamide-containing chelating fiber $\mathrm{Au}$ (III) is obviously loaded to a higher extent relative to the other noble metals.

Table II Characteristics and Element Content (\%) of Various Fibers

\begin{tabular}{|c|c|c|c|c|c|}
\hline & Color & Hardness & Oxygen & Nitrogen & Sulfur \\
\hline PANF & White & Soft & 7.18 & 23.58 & - \\
\hline Hydrazine-modified fiber & Light yellow & Soft & 6.83 & 25.90 & - \\
\hline Aminated fiber & Pink & Softer & 16.71 & 23.23 & - \\
\hline Imidazoline-containing fiber & Pink & Harder & 13.70 & 14.47 & - \\
\hline Thioamide-containing fiber & Yellow & Softer & 11.48 & 16.44 & 6.52 \\
\hline
\end{tabular}




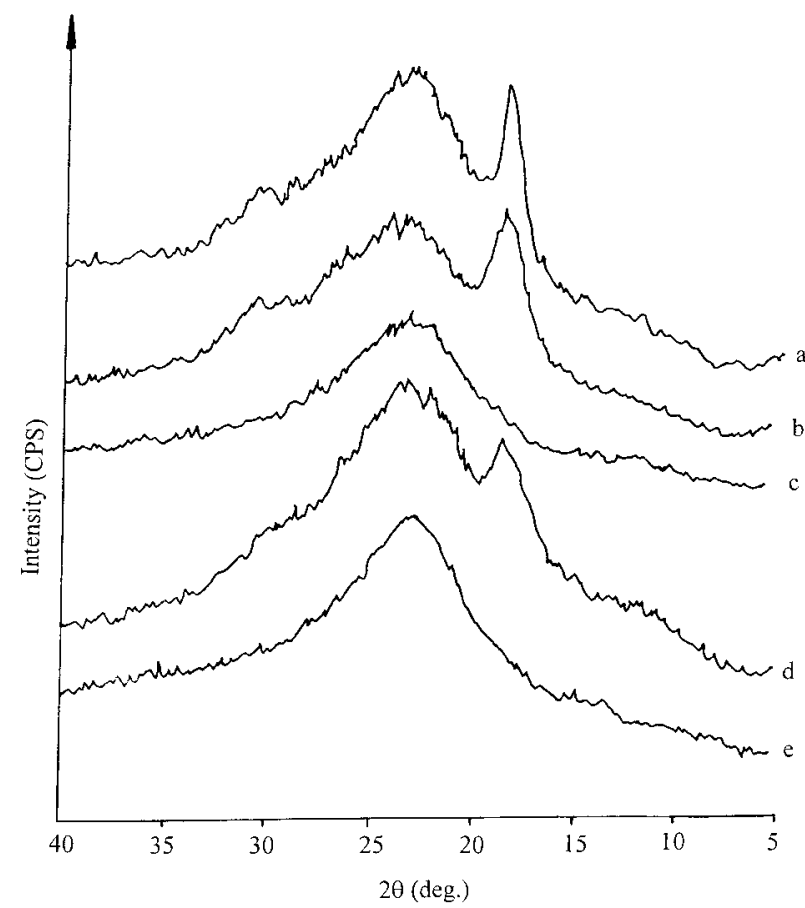

Figure 4 X-ray diffraction spectra of PANF (spectrum a), hydrazine-modified fiber (spectrum b), imidazoline-containing chelating fiber (spectrum c), aminated fiber (spectrum d), and thioamide-containing chelating fiber (spectrum e).

The distribution coefficients for noble metals on the imidazoline- and thioamide-containing chelating fibers, as well as PANF, are calculated in the usual way as the quotient of the equilibrium concentration of metal ions on the sorbent and in the aqueous phase. The $D$ values are summarized in Table IV. Obviously, Au(III), Pd(II), $\mathrm{Pt}(\mathrm{IV}), \mathrm{Os}(\mathrm{IV}), \mathrm{Ru}(\mathrm{IV}), \mathrm{Ir}(\mathrm{IV})$, and $\mathrm{Rh}(\mathrm{III})$ ions are remarkably sorbed by the two types of modified fibers, even at high $\mathrm{HCl}$ concentration while
Table IV Distribution Coefficients of Noble Metals with Imidazoline- or ThioamideContaining Chelating Fibers and PANF in Diluted Hydrochloric Acid

\begin{tabular}{llll}
\hline & \multicolumn{3}{c}{ HCl Concentration (mol/L) } \\
\cline { 2 - 4 } Metals & 0.1 & 0.5 & 2.0 \\
\hline \multicolumn{3}{c}{ PANF } \\
& \multicolumn{3}{c}{} \\
$\mathrm{Au}(\mathrm{III})$ & 1.02 & 0.789 & 0.842 \\
$\mathrm{Pd}(\mathrm{II})$ & 0.851 & 0.541 & 0.538 \\
$\mathrm{Pt}(\mathrm{IV})$ & 1.66 & 1.64 & 0.954 \\
$\mathrm{Ir}(\mathrm{IV})$ & 2.03 & 1.68 & 0.765 \\
$\mathrm{Os}(\mathrm{IV})$ & 1.42 & 1.41 & 1.21 \\
$\mathrm{Rh}(\mathrm{III})$ & 0.342 & 0.512 & 1.28 \\
$\operatorname{Ru}(\mathrm{IV})$ & 0.254 & 0.324 & 0.114
\end{tabular}

Thioamide-Containing Chelating Fiber

$\begin{array}{lccc}\mathrm{Au}(\mathrm{III}) & 1.90 \times 10^{5} & 1.45 \times 10^{5} & 1.47 \times 10^{5} \\ \mathrm{Pd}(\mathrm{II}) & 1.10 \times 10^{2} & 1.30 \times 10^{2} & 1.54 \times 10^{2} \\ \mathrm{Pt}(\mathrm{IV}) & 4.00 \times 10^{4} & 4.80 \times 10^{3} & 6.64 \times 10^{2} \\ \mathrm{Ir}(\mathrm{IV}) & 2.66 \times 10^{2} & 1.62 \times 10^{2} & 79.6 \\ \mathrm{Os}(\mathrm{IV}) & 1.68 \times 10^{3} & 2.65 \times 10^{2} & 1.04 \times 10^{2} \\ \mathrm{Rh} \text { (III) } & 40.7 & 38.1 & 34.9 \\ \mathrm{Ru}(\mathrm{IV}) & 18.7 & 22.6 & 25.4\end{array}$

Imidazoline-Containing Chelating Fiber

\begin{tabular}{llll}
$\mathrm{Au}(\mathrm{III})$ & $3.68 \times 10^{4}$ & $3.29 \times 10^{4}$ & $1.88 \times 10^{3}$ \\
$\mathrm{Pd}(\mathrm{II})$ & $6.58 \times 10^{4}$ & $3.99 \times 10^{4}$ & $1.36 \times 10^{3}$ \\
$\mathrm{Pt}(\mathrm{IV})$ & $3.64 \times 10^{4}$ & $8.01 \times 10^{3}$ & $3.64 \times 10^{2}$ \\
$\mathrm{Ir}(\mathrm{IV})$ & $2.36 \times 10^{4}$ & $1.24 \times 10^{4}$ & $3.25 \times 10^{3}$ \\
$\mathrm{Os}(\mathrm{IV})$ & $3.01 \times 10^{4}$ & $3.21 \times 10^{3}$ & $6.19 \times 10^{2}$ \\
$\mathrm{Rh}(\mathrm{III})$ & $4.95 \times 10^{2}$ & $5.78 \times 10^{2}$ & $1.17 \times 10^{2}$ \\
$\mathrm{Ru}(\mathrm{IV})$ & $6.80 \times 10^{2}$ & $2.67 \times 10^{2}$ & $1.46 \times 10^{2}$ \\
\hline
\end{tabular}

$\mathrm{Au}$ (III) ion is adsorbed more effectively by the thioamide-containing chelating fiber with a S-donor atom. It is also observed that the $D$ data of

Table III Binding Capacity of Fibrous Sorbents for Noble Metals in $0.1 \mathrm{~mol} / \mathrm{L} \mathrm{HCl}$

\begin{tabular}{|c|c|c|c|c|c|c|}
\hline \multirow{2}{*}{$\begin{array}{l}\text { Noble } \\
\text { Metals }\end{array}$} & \multicolumn{2}{|c|}{ PANF } & \multicolumn{2}{|c|}{$\begin{array}{c}\text { Thioamide-Containing } \\
\text { Fiber }\end{array}$} & \multicolumn{2}{|c|}{$\begin{array}{c}\text { Imidazoline-Containing } \\
\text { Fiber }\end{array}$} \\
\hline & $\mathrm{mmol} / \mathrm{g}$ & $\mathrm{mg} / \mathrm{g}$ & $\mathrm{mmol} / \mathrm{g}$ & $\mathrm{mg} / \mathrm{g}$ & $\mathrm{mmol} / \mathrm{g}$ & $\mathrm{mg} / \mathrm{g}$ \\
\hline $\mathrm{Au}(\mathrm{III})$ & 0.0179 & 3.52 & 2.74 & 539.0 & 3.68 & 724.0 \\
\hline $\operatorname{Pd}(\mathrm{II})$ & 0.0135 & 1.44 & 0.113 & 12.00 & 1.70 & 180.8 \\
\hline $\mathrm{Pt}(\mathrm{IV})$ & 0.00780 & 1.56 & 0.778 & 151.9 & 0.940 & 184.3 \\
\hline $\operatorname{Ir}(\mathrm{IV})$ & 0.00338 & 0.650 & 0.120 & 23.15 & 1.02 & 195.9 \\
\hline $\mathrm{Os}(\mathrm{IV})$ & 0.0110 & 2.10 & 0.166 & 31.58 & 1.03 & 194.9 \\
\hline Rh(III) & 0.00860 & 0.885 & 0.129 & 13.32 & 0.870 & 89.80 \\
\hline $\mathrm{Ru}(\mathrm{IV})$ & 0.00120 & 0.121 & 0.0610 & 6.150 & 0.680 & 69.10 \\
\hline
\end{tabular}




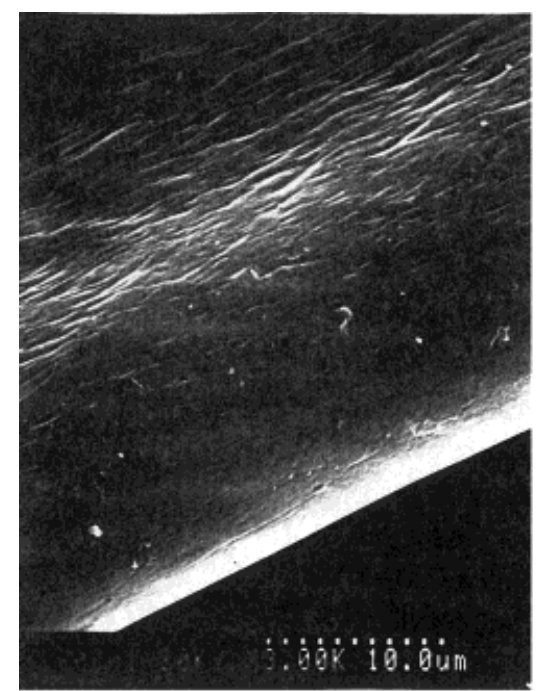

a

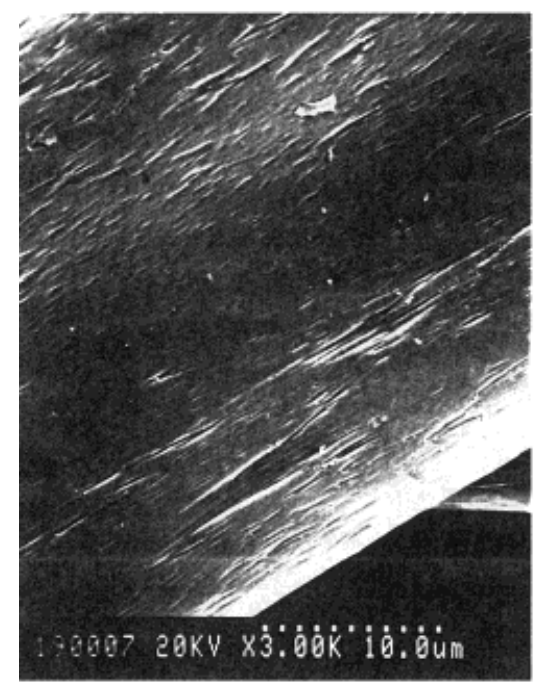

c

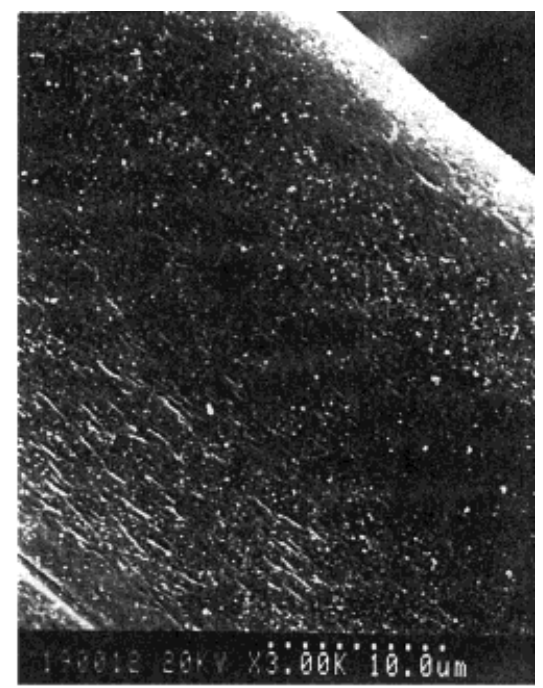

$\mathrm{b}$

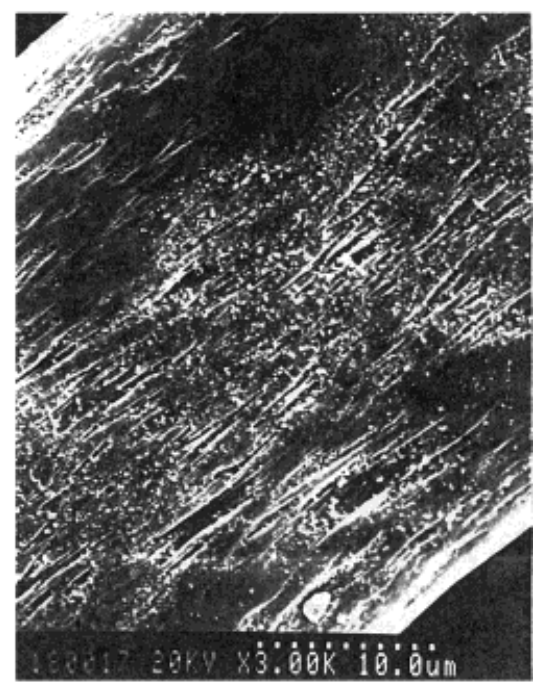

d

Figure 5 SEM photographs of (a) imidazoline-containing chelating fiber, (b) imidazoline-containing chelating fiber exposed to $\mathrm{Au}$ (III) solutions, (c) thioamide-containing chelating fiber, and (d) thioamide-containing chelating fiber exposed to $\mathrm{Au}(\mathrm{III})$ solutions.

$\mathrm{Rh}(\mathrm{III})$ and $\mathrm{Ru}(\mathrm{IV})$ with the two kinds of chelating fibers are remarkably low, corresponding to the other ions in the range of $\mathrm{HCl}$ concentrations studied, which may be caused by the relatively poor dependence on and possibility of forming complexes for $\mathrm{Rh}(\mathrm{III})$ and $\mathrm{Ru}(\mathrm{IV})$ with ligands.

\section{Reduction Properties of Au(III) on Chelating Fibers}

SEM examinations of the thioamide- and the imidazoline-containing chelating fibers either exposed or not to $\mathrm{Au}(\mathrm{III})$ solutions are undertaken to acquire additional insight into the sorption mechanisms of $\mathrm{Au}$ (III) ions by the chelating fibers. From SEM images of the studied sorbents (Fig. 5) we noted that many small particles are formed on the two kinds of $\mathrm{Au}$ (III)-loaded fibrous sorbents. This can be explained as a reduction of $\mathrm{Au}(\mathrm{III})$ to $\mathrm{Au}(\mathrm{I})$ then to $\mathrm{Au}(0)$ on the surface of the chelating fibers. To verify this explanation, X-ray diffraction spectra of the $\mathrm{Au}(\mathrm{III})$-loaded chelating fibers are recorded in the diffraction angle range of $30-80^{\circ} \mathrm{C}$. As shown in Figure 6, four diffraction 


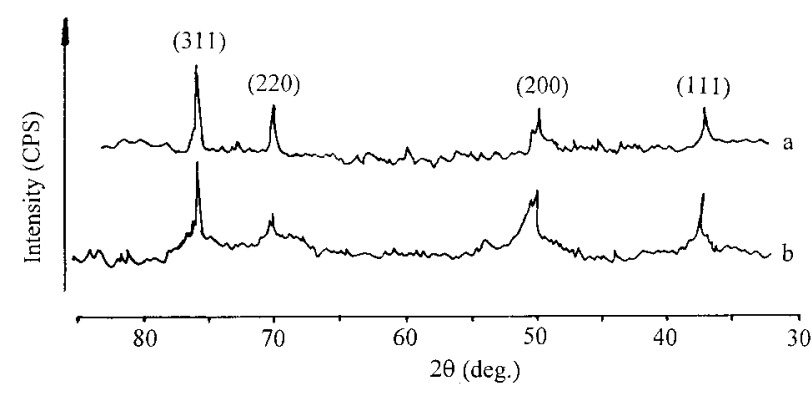

Figure 6 X-ray diffraction spectra of imidazoline-containing chelating fiber exposed to $\mathrm{Au}(\mathrm{III})$ solutions (spectrum a) and thioamide-containing chelating fiber exposed to $\mathrm{Au}(\mathrm{III})$ solutions (spectrum b).

peaks, corresponding to the crystal faces of $\mathrm{Au}(0)$ as (111), (200), (220), and (311), are present in the spectra of $\mathrm{Au}(\mathrm{III})$-loaded chelating fibers with thioamide and imidazoline groups. Thus, the reduction properties of $\mathrm{Au}(\mathrm{III})$ on the thioamideand imidazoline-containing chelating fibers are further proved.

\section{CONCLUSION}

The two types of chelating fibers containing a thioamide group or an imidazoline group are readily prepared. The reaction temperature, time, and agent concentration have different effects on the reaction efficiency at various reaction stages. With synthetic reaction processing the mechanical and surface properties of the chelating fibers exhibit an insignificant difference compared to those of the raw PANF, although the crystalline character of the chelating fibers becomes inferior. The functional groups of the products obtained during the reaction process are confirmed by IR spectroscopy analysis. In addition, the two kinds of newly developed fibrous sorbents show high sorption capacities toward noble metals in a high acidity and may provide useful applications in analytical chemistry or hydrometallurgy as well. Also, the results of our experiments demonstrate a reduction property of $\mathrm{Au}$ (III) on the chelating fibers. The reduction mechanism will be further investigated.

\section{REFERENCES}

1. Myasodova, G. C.; Savvin, S. B. CRC Crit Rev Anal Chem 1986, 17, 1.

2. Lee, G. H.; Chung, K. S. Analyst 1990, 155, 965.

3. Kallmann, S. Talanta 1986, 33, 75.

4. Shcherbinina, N. I.; Myasoedova, G. V.; Khabazova, T. A.; Danilova, E. Y.; Shvoeva, O. P.; Ishmiyarova, G. R.; Nikitina, I. E.; Bannykh, L. N. Zh Anal Khim 1990, 45, 2137.

5. Chang, X. J.; Su, Z. X.; Zhan, G. Y.; Luo, X. Y.; Gao, W. Y. Analyst 1994, 119, 1445.

6. Ge, X. P.; Zhang, B. W.; Grote, M. Mikrochim Acta 1998, 129, 303.

7. Lin, X.; Yang, Y. Z.; He, B. L. Ion Exchange Adsorption 1991, 7, 167.

8. Su, Z. X.; Chang, X. J. Talanta 1995, 42, 1127.

9. Grote, M.; Kettrup, A. Anal Chim Acta 1985, 172, 223.

10. Grote, M.; Kettrup, A. Anal Chim Acta 1985, 172, 239.

11. Zhang, B. W.; Wang, X. F.; Ge, X. P. Ion Exchange Adsorption 1992, 8, 52.

12. Vernon, F.; Shah, T. React Polym 1983, 1, 301.

13. Zverev, M. P. Chemosorptive Fibers [in Russian]; Khimiya: Moscow, 1981; p 191.

14. Liu, R. X.; Tang, H. X.; Zhang, B. W. Chemosphere 1999, 38, 3169.

15. Zhang, T. H.; Shan, X. Q.; Liu, R. X.; Tang, H. X. Anal Chem 1998, 70, 3964.

16. Li, Y.; Liu, R. X.; Zhang, B. W. Fresenius J Anal Chem 2000, 366, 821.

17. Wen, B.; Shan, X. Q.; Liu, R. X.; Tang, H. X. Fresenius J Anal Chem 1999, 365, 251.

18. Zhang, B. W.; Fischer, K.; Bieniek, D.; Kettrup, A. React Polym 1994, 24, 49.

19. Liu, R. X.; Zhang, B. W.; Tang, H. X. React Polym 1999, 39, 71.

20. Lin-Vien, D.; Colthup, N. B.; Fateley, W. G.; Grasselli, J. G. The Handbook of Infrared and Raman Characteristic Frequencies of Organic Molecules; Academic: San Diego, 1991.

21. Socrates, G. Infrared Characteristic Group Frequencies Tables and Charts, 2nd ed.; Wiley: Chichester, U.K., 1994.

22. Xu, Y. W.; Li, J.; Dong, S. H. Acta Polym Sinica 1993, 5, 576. 